\title{
Is routine chest radiography necessary after ultrasonography-guided catheter thoracostomy?
}

\author{
Yong Quan Alvin $\underline{\text { Soon }}^{1}$, MBBS, FRCR, Kian Wei Alvin $\underline{T a n}^{2}$, MBBS, Lakshmi Kumar ${ }^{2}$, MBBS, Uei $\underline{\text { Pua }}{ }^{1}$, MBBS, FRCR
}

INTRODUCTION Many institutions still perform routine chest radiography (CXR) after tube thoracostomies despite current guidelines suggesting that this is not necessary for simple cases. We aimed to evaluate the usefulness of routine CXR following ultrasonography-guided catheter thoracostomies for the detection of complications of symptomatic pleural effusions in hospitalised patients.

METHODS This was a retrospective review of 2,032 ultrasonography-guided thoracostomies on hospitalised patients with symptomatic effusions at a single institution from April 2012 to May 2015. The aetiology of effusions was not systemically registered, but patient demographics, procedural details and clinical outcomes were collected. Data was analysed using descriptive statistics and chi-square test. Generalised estimating equation analysis was performed to assess the relationship between CXR findings and complications while controlling for age.

RESULTS Out of 2,032 CXRs, 92.96\% ( $n=1,889)$ were normal, $5.81 \%(n=118)$ showed pneumothorax and $1.23 \%$ $(n=25)$ showed catheter kinking. 99 pneumothoraces and 24 kinked catheters were detected in the first hour post procedure. $97.40 \%(n=115)$ of patients with pneumothorax were stable or had minor complications, such as a vasovagal event. $0.20 \%(n=4)$ of the cases had a serious complication following chest drain insertion, resulting in cardiovascular collapse. There was no significant relationship between CXR results and occurrence of complications $(p=0.244)$. Amount of fluid drained or side of insertion did not affect the clinical outcome.

CONCLUSION Routine use of CXR after tube thoracostomy did not significantly change patient management, which was concordant with recent guidelines. Instead, adverse clinical outcomes or procedural factors should guide investigations.

Keywords: drainage, pleural effusion, pneumothorax, thoracostomy, ultrasound

\section{INTRODUCTION}

Small-bore catheters (7-14 Fr) have been gaining popularity in recent years for treatment of symptomatic effusions. ${ }^{(1)}$ Current practice guidelines do not require chest radiography to be performed after simple pleural aspiration unless air was withdrawn, the procedure was difficult, multiple attempts were required, or the patient became symptomatic. (1) Several studies have also shown that the incidence of post-procedure complications of ultrasonographyguided drainage of pleural effusions is low,,$^{(1-7)}$ with few clinically significant events that require urgent intervention. ${ }^{(8)}$ Furthermore, it has been shown that the insertion of pigtail catheters results in low complication rates when compared to large-bore chest tubes. ${ }^{(1,9-11)}$ It has been our department's experience that smallbore catheter insertion under ultrasonography guidance results in accurate positioning and minimal complications in the setting of symptomatic pleural effusions. However, many institutions continue to routinely perform chest radiography following tube thoracostomy despite recommendations by existing guidelines. The objective of this study was to assess the value of routine chest radiography after ultrasonography-guided catheter thoracostomies for the detection of complications of symptomatic pleural effusions in hospitalised patients.

\section{METHODS}

This study was approved by the institutional ethics review board. A retrospective review of the radiology information system database at the Department of Diagnostic Radiology, Tan Tock Seng Hospital, Singapore, was performed. All ultrasonographyguided pleural drainage procedures performed by interventional radiologists at our department for hospitalised patients with symptomatic effusions from April 2012 to May 2015 were selected. Chest radiography was routinely performed at our institution after pleural drainage. The aetiology of effusions was not systemically registered. Data on patient demographics, side of tube insertion, size of tube used, amount of fluid drained, time interval of the radiograph from the completion of procedure, radiography findings, and clinical outcomes was collected.

During the 37-month study period, 2,050 ultrasonographyguided pleural drainages were performed on 1,539 patients. 18 pleural procedures on 13 patients were excluded, as postprocedure chest radiography was not performed. A total of 2,032 ultrasonography-guided catheter thoracostomies performed on 1,526 patients were thus included for analysis. Each thoracostomy was considered as a unit of analysis.

For the small-bore pigtail catheter insertion technique, catheters were inserted under direct ultrasonography guidance. First, the drainage site was determined by ultrasonography, identifying the main collection of pleural fluid. Local anaesthesia was administered into the chest wall. Subsequent insertion of an 18-G Surflo venula (Terumo, Tokyo, Japan) into the pleural cavity was performed under direct ultrasonographic guidance. After confirmatory aspiration of the pleural fluid, a J-tipped

${ }^{1}$ Department of Diagnostic Radiology, Tan Tock Seng Hospital, ${ }^{2}$ Yong Loo Lin School of Medicine, National University of Singapore, Singapore

Correspondence: Dr Alvin Soon, Department of Diagnostic Radiology, Tan Tock Seng Hospital, 11 Jalan Tan Tock Seng, Singapore 308433. alvin_yq_soon@ttsh.com.sg 
guidewire was inserted into the pleural cavity after removal of the stylet. Sequential soft-tissue dilators were used to dilate the tract before passing the small-bore pleural catheter of choice into the pleural cavity. The final catheter position was determined by ultrasonography before the catheter was finally secured with anchoring sutures to a stoma base plate. Up to $1 \mathrm{~L}$ of pleural fluid was hand aspirated in most cases before clamping the drainage catheter. The drainage catheter was immediately connected to an underwater seal. A post-procedure chest radiograph was obtained.

Data was analysed using descriptive statistics. Comparison between two groups was carried out using chi-square test. Generalised estimating equation statistical analysis was performed to assess the relationship between chest radiography findings and complications, while controlling for age. The analyses were performed using IBM SPSS Statistics version 22.0 (IBM Corp, Armonk, NY, USA).

\section{RESULTS}

There were 894 (58.58\%) men and 632 (41.42\%) women, with a mean age of $67 \pm 14$ (range 17-102) years. Pigtail catheters in the range of 8-14 Fr were used for pleural drainage. 99.61\% $(n=2,024)$ of the catheters used were 10-Fr Navarre (Bard, NJ, USA) or ReSolve (Merit Medical, UT, USA) catheters. $89.22 \%$ of the post-procedure radiographs were obtained within an hour and $97.44 \%$ within four hours of the ultrasonography-guided catheter thoracostomy (Table I). Chest radiography was performed more than 12 hours after the catheter thoracostomy in only $0.74 \%(n=15)$ of the pleural procedures; among these, one patient had cardiovascular collapse.

$92.96 \%(n=1,889)$ of chest radiographs were normal, while $5.81 \%(n=118)$ showed pneumothorax and $1.23 \%(n=25)$ had catheter kinking (Table I). 99 pneumothoraces and 24 kinked catheters were detected in the first hour post procedure. $97.40 \%$ $(n=115)$ of patients with pneumothorax were stable or had minor complications, such as a vasovagal event (Table II).
$0.20 \%(n=4)$ of the cases had a serious complication following chest drain insertion, with eventual cardiovascular collapse, as detailed in Table III. Among these patients, three demonstrated pneumothorax on the post-procedure radiograph, while one patient had a normal chest radiograph. Three of these patients had radiography performed within an hour of the procedure, while the fourth patient had radiography performed 12-24 hours after the procedure. There was no significant relationship between chest radiography findings and the occurrence of complications ( $p=0.244$ ).

$60.68 \%(n=1,233)$ of the procedures were performed by staff radiologists with at least five years of post-fellowship experience, and $39.32 \%(n=799)$ were performed by radiology residents under supervision. Residents had a statistically significant higher rate of complications. Pneumothorax occurred in 7.51\% (60/799) of procedures performed by residents, compared to $4.70 \%$ $(58 / 1,233)$ of procedures performed by staff radiologists $(p<0.05)$.

During ultrasonography-guided pleural drainage, the amount of fluid drained was as follows: $<100 \mathrm{~mL}$ in 209 (10.29\%) cases, $100-250 \mathrm{~mL}$ in 371 (18.26\%) cases, $251-500 \mathrm{~mL}$ in 437 (21.51\%) cases, $501-750 \mathrm{~mL}$ in 329 (16.19\%) cases, $751-1,000 \mathrm{~mL}$ in $407(20.03 \%)$ cases, $1,001-1,500 \mathrm{~mL}$ in $39(1.92 \%)$ cases and $>1,500 \mathrm{~mL}$ in $5(0.25 \%)$ cases. For $235(11.56 \%)$ cases, the amount of fluid drained was not recorded in the procedural notes. $773(38.04 \%)$ cases had drainage in the left hemithorax and 1,259 (61.96\%) cases had drainage in the right hemithorax. There was no significant relationship between the volume of fluid drained $(p=0.10)$ or the side of drain insertion $(p=0.740)$ and the occurrence of complications.

Subgroup analysis of pleural procedures with kinked tubes ( $\mathrm{n}=25$ ) demonstrated that the amount of fluid drained was as follows: $<100 \mathrm{~mL}$ in $8(32.00 \%)$ cases, $100-250 \mathrm{~mL}$ in $8(32.00 \%)$ cases, $251-500 \mathrm{~mL}$ in $2(8.00 \%)$ cases, $501-750 \mathrm{~mL}$ in $2(8.00 \%)$ cases and $751-1,000 \mathrm{~mL}$ in $3(12.00 \%)$ cases. For $2(8.00 \%)$ cases, the amount of fluid drained was not recorded in the procedural notes.

Table I. Time of chest radiography (CXR) after the procedure and findings $(n=2,032)$.

\begin{tabular}{|llll|}
\hline $\begin{array}{l}\text { Time of CXR } \\
\text { after insertion }(\mathbf{h r})\end{array}$ & \multicolumn{2}{c|}{ No. (\%) } \\
\cline { 2 - 4 } & Pneumothorax & Catheter kinking & Normal \\
\hline$<1$ & $99(4.90)$ & $24(1.20)$ & $1,690(83.17)$ \\
\hline $1-4$ & $9(0.40)$ & $1(0.05)$ & $157(7.73)$ \\
\hline $4-12$ & $7(0.30)$ & $0(0)$ & $30(1.48)$ \\
\hline $12-24$ & $1(0.05)$ & $0(0)$ & $6(0.30)$ \\
\hline$>24$ & $2(0.10)$ & $0(0)$ & $6(0.30)$ \\
\hline Total & $118(5.81)$ & $25(1.23)$ & $1,82)$ \\
\hline
\end{tabular}

Table II. Chest radiography (CXR) findings and clinical outcomes $(n=2,032)$.

\begin{tabular}{|c|c|c|c|c|}
\hline \multirow[t]{2}{*}{ CXR finding } & \multicolumn{4}{|c|}{ No. (\%) } \\
\hline & Stable & Vasovagal event & Cardiovascular collapse & Total \\
\hline Pneumothorax & $112(5.51)$ & $3(0.15)$ & $3(0.15)$ & $118(5.81)$ \\
\hline Catheter kinking & $25(1.23)$ & $0(0)$ & $0(0)$ & $25(1.23)$ \\
\hline Normal & $1,847(90.90)$ & $41(2.02)$ & $1(0.05)$ & 1,889 (92.96) \\
\hline Total & $1,963(96.60)$ & $44(2.17)$ & $4(0.20)$ & $2,032(100.00)$ \\
\hline
\end{tabular}


Table III. Overall data of patients with cardiovascular collapse subsequent to chest drain insertion $(n=4)$.

\begin{tabular}{|c|c|c|c|c|c|c|c|}
\hline No. & $\begin{array}{l}\text { Age/ } \\
\text { gender }\end{array}$ & Indication & $\begin{array}{l}\text { Chest drain } \\
\text { detail (size/side) }\end{array}$ & $\begin{array}{l}\text { Timing of chest } \\
\text { radiography after } \\
\text { insertion }(\mathrm{hr})\end{array}$ & $\begin{array}{l}\text { Vol. of fluid } \\
\text { drained }(\mathrm{mL})\end{array}$ & $\begin{array}{l}\text { Chest radiography } \\
\text { finding }\end{array}$ & $\begin{array}{l}\text { Cause of cardiovascular } \\
\text { collapse }\end{array}$ \\
\hline 1 & $86 / \mathrm{M}$ & $\begin{array}{l}\text { Pleural } \\
\text { effusion }\end{array}$ & $10 \mathrm{Fr}$, left & $<1$ & 1,000 & Pneumothorax & $\begin{array}{l}\text { Metastatic adenocarcinoma } \\
\text { complicated by fluid overload, } \\
\text { end-stage renal failure } \\
\text { and healthcare-associated } \\
\text { pneumonia }\end{array}$ \\
\hline 2 & $51 / \mathrm{M}$ & $\begin{array}{l}\text { Pleural } \\
\text { effusion }\end{array}$ & $10 \mathrm{Fr}$, right & $<1$ & 250 & Normal & $\begin{array}{l}\text { End-stage renal failure with fluid } \\
\text { overload and diabetes mellitus } \\
\text { complicated by healthcare- } \\
\text { associated pneumonia }\end{array}$ \\
\hline 3 & $70 / \mathrm{M}$ & $\begin{array}{l}\text { Pleural } \\
\text { effusion }\end{array}$ & $10 \mathrm{Fr}$, right & $<1$ & 50 & Pneumothorax & $\begin{array}{l}\text { Metastatic small cell lung } \\
\text { cancer complicated by superior } \\
\text { vena cava obstruction }\end{array}$ \\
\hline 4 & $53 / \mathrm{M}$ & $\begin{array}{l}\text { Pleural } \\
\text { effusion }\end{array}$ & $10 \mathrm{Fr}$, left & $<24$ & 430 & Pneumothorax & $\begin{array}{l}\text { Polytrauma from motor } \\
\text { vehicle accident }\end{array}$ \\
\hline
\end{tabular}

Fr: French; M: male

\section{DISCUSSION}

Ultrasonography-guided thoracocentesis ${ }^{(5,8,12)}$ and tube thoracostomy ${ }^{(2,3,11,13)}$ are safe procedures with few complications. A majority of complications in our patients were detected on post-procedure chest radiography performed within the first hour. However, these complications were not clinically significant, with no cardiovascular collapse noted. Suboptimal catheter placement with kinking will result in poor fluid drainage or resistance to aspiration, which may prompt further investigations. The kinked tubes were repositioned within 24 hours of detection. These tubes were initially assessed to have adequate flow on hand aspiration during the procedure. Movement of the tubes during patient transfer and transport could have occurred despite the anchoring suture, resulting in poor drainage in the wards. The pneumothoraces in patients who developed kinked tubes were small (less than $3 \mathrm{~cm}$ apex to cupola distance) and resolved after observation or oxygen therapy; these cases did not require invasive intervention.

Our findings suggest that instead of having routine chest radiography following ultrasonography-guided catheter thoracostomies, considerations about performing post-procedure chest radiography should be guided by procedural factors (e.g. withdrawal of air, difficult procedure and multiple attempts), ${ }^{(1)}$ the patient's clinical conditions and/or catheter performance. Unstable or deteriorating blood pressure, oxygen saturation or increased oxygen requirement should prompt further investigations. In patients who had cardiovascular collapse in our study, the detection of abnormalities did not predict impending collapse. Incidentally, in one patient who collapsed, the post-procedure chest radiograph was normal. Several authors ${ }^{(7,8,14,15)}$ have arrived at similar conclusions that post-procedure chest radiography should be guided by clinical symptoms. Our findings also concur with the existing British Thoracic Society (BTS) guidelines on pleural disease. ${ }^{(1)}$

Varying amounts of pleural fluid were drained from patients in this study. In our practice, this is guided by the size of pleural effusion, whether the patient becomes symptomatic during initial drainage (either coughing or breathlessness), and whether resistance and poor drain performance was encountered during initial drainage. We generally adhere to BTS guidelines as part of our departmental practice, draining up to $1 \mathrm{~L}$ of pleural fluid in order to reduce the risk of re-expansion pulmonary oedema. $44(2.17 \%)$ cases had over $1 \mathrm{~L}$ of pleural fluid drained during the procedure in our study. However, no documentation was available for these patients to account for the increased volumes of drainage. Some practitioners may drain more than $1 \mathrm{~L}$ for patients with very large recurrent symptomatic pleural effusions to the point of symptom relief, on a case-by-case basis.

Subgroup analysis of chest radiographs with kinked catheters revealed that $64.0 \%(16 / 25)$ had drainage volumes of less than $250 \mathrm{~mL}$. This would suggest that in patients with small pleural effusions, it might be difficult to position the catheters in the optimal position due to less space for manipulation.

In our study, a majority of radiographs were normal. Among procedures with abnormal radiographs, nearly all patients were stable and abnormalities were clinically insignificant. For patients who had post-procedure cardiovascular collapse, the radiographs did not provide sufficient information to warn of the impending collapse. The patients who collapsed after catheter insertion were individually reviewed and shown to have severe comorbidities, such as metastatic lung cancer, severe pneumonia, end-stage renal failure with fluid overload, and polytrauma with severe injuries. These patients had cardiovascular collapse and died more than 24 hours post procedure.

It was also noted that procedures performed by residents had a statistically significant higher rate of complications. This may be due to prolonged procedure time, resulting in more manipulation. However, post-procedure chest radiography was still not warranted for such patients, as the number of pneumothoraces encountered in our study was not clinically significant.

In conclusion, this large-scale, single-centre retrospective study suggested that chest radiography findings following ultrasonography-guided catheter thoracostomies do not often 
change patient management, which is concordant with the 2010 BTS guidelines. ${ }^{(1)}$ Instead, procedural factors and clinical outcomes such as unstable vital signs or poor drainage should guide further investigations in these hospitalised patients. Additional studies may be performed to evaluate reduction in radiation exposure, as well as associated cost savings if postprocedure radiographs were to be omitted for these patients.

\section{ACKNOWLEDGEMENTS}

We thank Ms Sun Bing and Ms Tang Xin from the Clinical Research and Innovation Office, Tan Tock Seng Hospital, Singapore, for their assistance with statistical analysis.

\section{REFERENCES}

1. Havelock T, Teoh R, Laws D, Gleeson F; BTS Pleural Disease Guideline Group. Pleural procedures and thoracic ultrasound: British Thoracic Society Pleural Disease Guideline 2010. Thorax 2010; 65 Suppl 2:ii61-76.

2. Horsley A, Jones L, White J, Henry M. Efficacy and complications of small-bore, wire-guided chest drains. Chest 2006; 130:1857-63.

3. Liu YH, Lin YC, Liang SJ, et al. Ultrasound-guided pigtail catheters for drainage of various pleural diseases. Am J Emerg Med 2010; 28:915-21.
4. Keeling AN, Leong S, Logan PM, Lee MJ. Empyema and effusion: outcome of image-guided small-bore catheter drainage. Cardiovasc Intervent Radiol 2008; 31:135-41.

5. Jones PW, Moyers JP, Rogers JT, et al. Ultrasound-guided thoracentesis: is it a safer method? Chest 2003; 123:418-23.

6. Capizzi SA, Prakash UB. Chest roentgenography after outpatient thoracentesis. Mayo Clin Proc 1998; 73:948-50.

7. Doyle JJ, Hnatiuk OW, Torrington KG, Slade AR, Howard RS. Necessity of routine chest roentgenography after thoracentesis. Ann Intern Med 1996; 124:816-20.

8. Mynarek G, Brabrand K, Jakobsen JA, Kolbenstvedt A. Complications following ultrasound-guided thoracocentesis. Acta Radiol 2004; 45:519-22.

9. Cooke DT, David EA. Large-bore and small-bore chest tubes: types, function, and placement. Thorac Surg Clin 2013; 23:17-24, v.

10. Fysh ET, Smith NA, Lee YC. Optimal chest drain size: the rise of the small-bore pleural catheter. Semin Respir Crit Care Med 2010; 31:760-8.

11. Gammie JS, Banks MC, Fuhrman CR, et al. The pigtail catheter for pleural drainage: a less invasive alternative to tube thoracostomy. JSLS 1999; 3:57-61.

12. Cavanna L, Mordenti $P$, Bertè $R$, et al. Ultrasound guidance reduces pneumothorax rate and improves safety of thoracentesis in malignant pleural effusion: report on 445 consecutive patients with advanced cancer. World J Surg Oncol 2014; 12:139.

13. Jain S, Deoskar RB, Barthwal MS, Rajan KE. Study of pigtail catheters for tube thoracostomy. Med J Armed Forces India 2006; 62:40-1.

14. Petersen WG, Zimmerman R. Limited utility of chest radiograph after thoracentesis. Chest 2000; 117:1038-42.

15. Alemán C, Alegre J, Armadans L, et al. The value of chest roentgenography in the diagnosis of pneumothorax after thoracentesis. Am J Med 1999; 107:340-3. 